\title{
Abundance and survival estimates of the southeastern Pacific humpback whale stock from 1991-2006 photo-identification surveys in Ecuador
}

\author{
Fernando Félix ${ }^{1}$, Cristina Castro² ${ }^{2}$ Jeffrey L. LaAkE ${ }^{3}$, Ben HaAse ${ }^{1}$ And Meike Scheidat ${ }^{4}$ \\ Contacte-mail:fefelix90@hotmail.com
}

\begin{abstract}
Southeastern Pacific humpback whales (Breeding Stock G) breed along the northwestern coast of South America and farther north up to Costa Rica. Photo-identification surveys conducted aboard whalewatching vessels during the migration/breeding season from June to September between 1991 and 2006 off the coast of Ecuador $\left(2^{\circ} \mathrm{S}, 81^{\circ} \mathrm{W}\right)$ have produced a database of 1,511 individual whales. Comparisons of photographs produced 190 between-year re-sightings of 155 individual whales. Closed and open capture-recapture models were used to estimate abundance and survival. The best estimate of abundance in 2006 with the Chapman modified-Petersen was 6,504 (95\% CI: 4,270-9,907; CV=0.21). Abundance estimates from open population models were considerably lower due to heterogeneity in capture probability which produced a 'transient' effect. Our best estimate of true survival was 0.919 (95\% CI: $0.850-0.958)$. Heterogeneity most likely occurred from inter-annual variation in sampling and unknown structure and variation in the migration timing and corridor. A more extensive collaborative effort including other wintering areas further north as well as integrating breeding-feeding data will help to reduce heterogeneity and increase precision in abundance and survival estimates.
\end{abstract}

KEY WORDS: HUMPBACK WHALE; ABUNDANCE ESTIMATE; SURVIVORSHIP; MARK-RECAPTURE; PHOTO-ID; SOUTH AMERICA.

\section{INTRODUCTION}

Humpback whales (Megaptera novaeangliae) migrate in the southeast Pacific between their feeding grounds located around the Antarctic peninsula (Stevick et al., 2004) and south of Chile (Gibbons et al., 2003) and their breeding grounds located along the coasts of Ecuador, Colombia, Panama and south of Costa Rica (Clarke, 1962; Félix and Haase, 2001a; Flórez-González, 1991; Rasmussen et al., 2007; Scheidat et al., 2000). This southern stock, also known as west South American or Breeding Stock G (IWC, 2006), was extensively exploited during the 20th Century in Antarctic waters and along the coasts of Chile and Peru until the mid-1960s (Clarke, 1980; Ramírez, 1988). Although for a long time the southeastern Pacific stock has been considered distinct from the other six southern Hemisphere stocks, its discreteness was only recently confirmed through molecular biology studies (Caballero et al., 2001; Olavarria et al., 2007) and photo-identification (Stevick et al., 2004). By the mid-1960s, it was thought that only a few hundred individuals remained in each southern humpback whale stock (Chapman, 1974). The current status and the level of recovery of the Southeast Pacific humpback whale stock are still poorly known.

The first attempts to estimate the size of the southeastern humpback whale stock at the breeding grounds were made during the mid-1980s around Gorgona Island, Colombia, using mark-recapture models (e.g. Capella et al., 1998; Flórez-González, 1991; Ojeda and Hurtado, 1992) and the coast of Ecuador using direct counts (Haase, 1990). As whalewatching activities developed by the mid-1990s, studies on humpback whales increased on the coast of Ecuador using tourist vessels as platforms of opportunity for research. This allowed several research groups to develop long-term photo-identification programs. New population estimates, albeit with wide confidence intervals, were obtained on the central coast of Ecuador using mark recapture models during the mid-1990s (Félix and Haase, $2001 \mathrm{~b}$; Scheidat et al., 2000) and early 2000s (Castro et al., 2004; 2003; 2005). These latter estimates indicated that the population contained around 3,000 whales in 2003. Recent mark-recapture estimates of Breeding Stock G using photoidentification data from both breeding and feeding grounds (Stevick et al., 2006) and from line transect data collected during the International Whaling Commission IDCR/SOWER circumpolar surveys (Branch, 2011) showed similar estimates $(3,851 \mathrm{CV}=0.02$ and $3,337 \mathrm{CV}=0.21$, whales respectively) by the mid-1990s. Photo-identification and genetic studies have demonstrated that a biased sex ratio occurs at breeding grounds, with males outnumbering females in a proportion of 1.67-1.95:1 (Olavarria et al., 2007; Palsbøll et al., 1997; Smith et al., 1999), which would explain the difference found between breeding and feeding grounds sampling approaches.

New abundance and survival estimates are presented here for the southeastern Pacific humpback whale stock using mark-recapture models for both closed and open populations. The database pools the data from two research teams and includes 16 years of fieldwork conducted off Ecuador. It is at least three times larger than those previously used in breeding-breeding estimates for this stock and as a result, the level of uncertainty was reduced considerably.

\section{The study area}

The study area includes two sites on the central coast of Ecuador. The northern site comprises $c a .700 \mathrm{~km}^{2}$ between La Plata Island and two fishing villages, Puerto López and Puerto Cayo $\left(1^{\circ} 26^{\prime} \mathrm{S}, 80^{\circ} 50^{\prime} \mathrm{W}\right)$. The latter two sites are located

\footnotetext{
${ }^{1}$ Museo de Ballenas, Av. Enríquez, Gallo entre Calles 47 y 50, Salinas, Ecuador.

${ }^{2}$ Pacific Whale Foundation, PO Box 17-21-872, Quito, Ecuador.

${ }^{3}$ National Marine Mammal Laboratory, AFSC, NMFS, 7600 Sand Point Way NE, Seattle, WA 98115, USA.

${ }^{4}$ Forschungs und Technologiezentrum Westkueste, Universität Kiel, 25761 Buesum, Germany.
} 


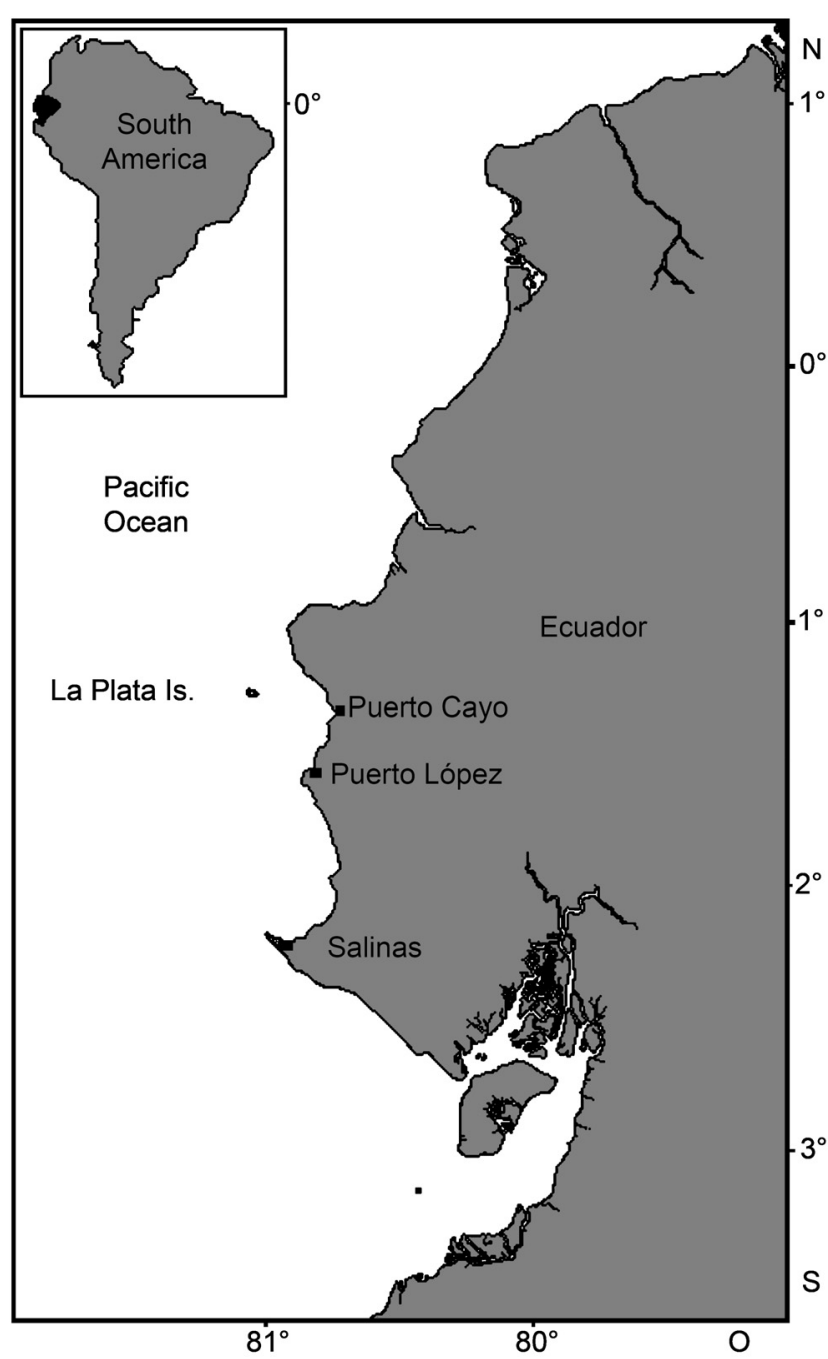

Fig. 1. The coast of Ecuador and the study sites.

$22 \mathrm{~km}$ apart whereas La Plata Island is located approximately $40 \mathrm{~km}$ offshore. The second study site is Salinas, located $80 \mathrm{~km}$ south of the former site $\left(2^{\circ} 10^{\prime} \mathrm{S}, 81^{\circ} 05^{\prime} \mathrm{W}\right)$ on the westernmost tip of the Santa Elena peninsula. The surveyed area in Salinas comprises around $150 \mathrm{~km}^{2}$ over a narrow platform around the peninsula (Fig. 1).

\section{MATERIAL AND METHODS}

\section{Survey effort}

Photographs of the ventral side of whales' flukes (see Katona et al., 1979) were obtained for individual identification during the breeding season (June-October) between 1991 and 2006 onboard whalewatching vessels. For this purpose, both film and digital cameras equipped $70-300 \mathrm{~mm}$ zoom lenses were used.

Vessels departed from three different ports: Puerto Lopez, Puerto Cayo and Salinas. In the first years, whalewatching trips were not conducted on a regular basis but were opportunistic, taking place when tourists were more numerous, especially on weekends. As the whalewatching industry became more established and more boats were available, trips were more regular and so the field season extended from a few days in the first years of the study to 69 days of fieldwork in 2006 off Salinas (Table 1). In Puerto López the sampling period has been continuous since 1991 and in Salinas since 2002. Puerto Cayo was sampled in only two field seasons (1996-1997), but for the same number of days as in Puerto López. In general, effort was more uniform after 2004 in both Puerto López and Salinas. Most of the effort within the season was concentrated in July and August ( $29 \%$ and $41 \%$ of the effort, respectively), then in September $(22 \%)$; only $7.62 \%$ of the trips were in the remaining three months sampled (May, June and October) (Table 2).

In Puerto López, trips lasted between 8 and 10 hours, including a 3-hour stop at La Plata Island and then a return to port in the evening. From 2002 a land station on top of a cliff was used for whale tracking and trips were conducted around La Plata during the 3-hour period that passengers visited the island. Researchers on the boat were guided to the whales by an observer from the coastal station. In Puerto Cayo, trips lasted 2-3 hours and were carried out mainly over a shallow platform west of the port. In Salinas, trips lasted between 2 and 3 hours and occasionally longer. In this port up to two trips were conducted per day during the peak of the tourist season. Additional information on the trip methodology and complementary data taken during the trips are available (e.g. Castro and González, 2002; Félix and Haase, 2001a; 2001b; 2005; Scheidat et al., 2000).

\section{Analysis of photographs}

Photographs used in this study are part of the catalogues maintained by the Ecuadorian Foundation for the Study of Marine Mammals (FEMM) and Pacific Whale FoundationEcuador (PWF), which contain multiple photographs of 1,839 different individuals.

The digitised catalogues were exchanged and analysed separately by the research teams of both institutions. Besides identifying common individuals, each group separated the photographs considered unsuitable for comparison due to poor quality (i.e. blurred, inappropriate angle) based on their expertise. However, no specific criteria for photographic quality or individual distinctiveness were used to evaluate photographs. Neither calves nor whales identified only by one lobe of the tail were included in the analysis. Photographs of 1,511 different adult individuals remained for the analysis $(82 \%$ of the total animals originally considered) covering 16 years. The comparison of photographs produced 190 between-year re-sightings of 155 individuals: 129 individuals were re-sighted once, 23 individuals twice, 2 individuals three times, 1 individual four times and 1 individual five times.

\section{Mark-recapture models}

Whales were considered to be 'captured' for the year (sampling occasion) if they were identified in a photograph from one or more trips that extended anywhere during the breeding season of each year. The 16 years of data were used to construct a capture-history for each of the 1,511 unique whales. The capture-history data were evaluated with models for closed and open populations and then the results were compared.

\section{Closed population}

Closed population models assume that the population is closed demographically and geographically (i.e. $N$ is constant), that all animals are equally catchable for specified subsets as defined by the model (e.g. during a sampling year), that marks are permanent and all marks are reported (Hammond, 1986; Seber, 1982). We used the Chapman (1951) modified-Petersen estimator for two occasions using consecutive field seasons 1996 and 1997 and from 2001 to 2006. 
Table 1

Annual effort and number of sightings made in each site (period 1991-2006).

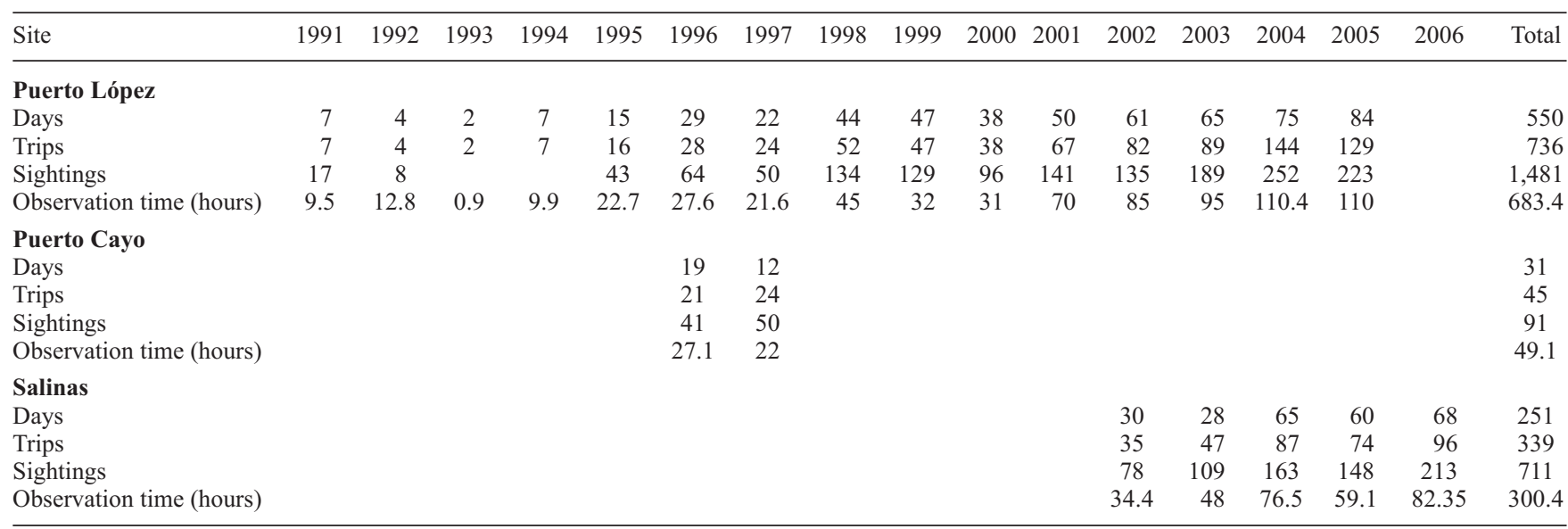

\section{Open population}

The POPAN formulation (Schwarz and Árnason, 1996) for the Jolly-Seber model was used in Program MARK (White and Burnham, 1999) to examine a series of proposed models for estimation of abundance and survival. Jolly-Seber models are used to represent open populations which allow gains from immigration and births, and losses from mortality and permanent emigration. The latter are confounded in the apparent survival parameters $\varphi$ which can be constant, timedependent or represented by any other appropriate structure. Capture-probability parameters, $p$, can also be constant, time-dependent or modelled with a covariate that is known for all members of the population. The abundance parameter $N$ is a super-population size which is the total number of animals that were in the population at some point during the study. Entry (immigration/birth) into the population in the POPAN formulation is represented by parameters pent which are probabilities that sum to 1 . The parameter pent $(0)$ is the proportion of $N$ that was in the population just prior to the beginning of the study. MARK provides estimates and standard errors of the size of the population at each sampling occasion (year) throughout the study.

As with models for closed populations, abundance estimators from open population models can underestimate abundance if there is any unmodelled heterogeneity in capture probability. In addition, apparent survival will be lower than true survival if there is any 'permanent' emigration during the course of the study. Any transient animals that appear only once and then leave the study area will also reduce apparent survival and will lower the abundance estimate. Both of these influences were potentially important issues in modelling the capturerecapture data collected in this study. The sampled whales included some that might remain in or near the study area during the breeding season ('local') and others that would only migrate through the area to breed farther north. Whales that migrate through the area might travel through the sampled area in one year and be photographed but they might take a different course from that point on and would appear to be transient. Whales migrating to the north could easily pass through the $100 \mathrm{~km}$ stretch of sampled coast in 1 to 2 days. Unless sampling occurred every day of the week many migrating whales would have 0 probability of being captured; whereas, whales that remained would have a much higher probability of being photographed. Undoubtedly, this was more important prior to 2004 when sampling occurred

Table 2

Effort deployed by month as number of days of fieldwork by the two research teams (FEMM and PWF) during the period 1991-2006.

\begin{tabular}{|c|c|c|c|c|c|c|c|c|c|c|c|c|}
\hline \multirow[b]{2}{*}{ Year } & \multicolumn{2}{|c|}{ May } & \multicolumn{2}{|c|}{ June } & \multicolumn{2}{|c|}{ July } & \multicolumn{2}{|c|}{ August } & \multicolumn{2}{|c|}{ September } & \multicolumn{2}{|c|}{ October } \\
\hline & FEMM & PWF & FEMM & PWF & FEMM & PWF & FEMM & PWF & FEMM & PWF & FEMM & PWF \\
\hline 1991 & & & & & 4 & & 2 & & 1 & & & \\
\hline 1992 & & & & & 1 & & 2 & & 1 & & & \\
\hline 1993 & & & & & & & 1 & & 1 & & & \\
\hline 1994 & & & 2 & & 2 & & 2 & & 1 & & & \\
\hline 1995 & & & & & 3 & & 4 & & 8 & & & \\
\hline 1996 & 1 & & 4 & & 7 & & 10 & & 7 & & & \\
\hline 1997 & & & 2 & & 7 & & 10 & 18 & 3 & 7 & & \\
\hline 1998 & & & & 1 & & 16 & & 22 & & 5 & & \\
\hline 1999 & & & & 13 & & 14 & & 15 & & 5 & & \\
\hline 2000 & & & & 1 & 5 & 11 & 2 & 13 & 1 & 5 & & \\
\hline 2001 & & & & 2 & & 5 & & 28 & & 15 & & \\
\hline 2002 & & & 3 & & 9 & 13 & 9 & 29 & 8 & 19 & 1 & \\
\hline 2003 & & & 1 & & 11 & 17 & 10 & 27 & 4 & 21 & 2 & \\
\hline 2004 & & & 4 & 3 & 21 & 25 & 24 & 29 & 14 & 18 & 2 & \\
\hline 2005 & & & 4 & 8 & 25 & 29 & 27 & 29 & 3 & 16 & 1 & 2 \\
\hline 2006 & & & 2 & & 14 & & 29 & & 19 & & 4 & \\
\hline Total & 1 & & 22 & 28 & 109 & 130 & 132 & 210 & 71 & 111 & 10 & 2 \\
\hline
\end{tabular}


primarily on weekends. To address these issues, at least partially, we considered models in which transient behaviour was accommodated by fitting a separate survival for the interval following the first sighting of a whale. We also used within-year resightings of whales to assign whales to 'local' versus 'migrant' groups. Whales were initially assumed to be migrants and were only assigned to the local group once they were resighted on more than one day within a year separated by at least 3 days and not more than 50 days, if only seen twice. Those values were chosen to accommodate a migrating whale being seen close together in time as it migrated through and others that might be seen migrating north and then south (>50 days). 'Local' whales were allowed to have a different and presumably higher capture probability for any year after their assignment to the local group.

We fitted and compared 36 POPAN models using the $\mathrm{R}$ ( $R$ Development Core Team, 2008) package RMark v1.7.7 (http://www.phidot.org/software/mark/rmark/; Laake and Rexstad, 2008) which constructs the model and runs MARK to fit the models. The 36 models were constructed from all combinations of the sub-models: 3 models for $p$ (constant, time, time + local), 3 models for $\varphi$ (constant, time, transient) and 4 models for pent (constant, time, time bins, and Timelinear trend). The 'time' model contains a parameter for each of the 16 years whereas the 'Time' model contains an intercept and slope and assumes a linear trend over time. The time bins for pent were constructed to create a simpler reduced model with constant probability of entry (except pent(0)) for 1991-2002 and a time-varying rate for years 2003 to 2006. These times were chosen to reflect the expanded effort throughout the week that began in 2003. Models weights were calculated using Akaike Information Criterion (AICc) (Burnham and Anderson, 2002) and estimates of abundance were averaged across the models with $\triangle \mathrm{AICc}<6$. Chi-square tests 2 and 3 for the recapturedata were computed from RELEASE as a guide for goodness of fit test of a general model with full time-dependent effects.

\section{RESULTS}

\section{Closed population model}

Estimates were constructed using the 1996-1997 samples and consecutive years between 2001 and 2006 (Table 3). Capture probability in the other years was too low to provide reliable results. The most precise estimates were obtained using the 2004-2006 data when sampling effort was quite extensive; however, those estimates were dramatically larger than the estimates prior to 2004 and the implied increase was not biologically plausible (see Clapham et al., 2001).

\section{Open population model}

The goodness-of-fit test of the fully time-dependent model did not suggest any important lack of fit $\left(\chi^{2}=42.0, \mathrm{df}=37\right.$, $\mathrm{p}=0.26)$. Of the 36 fitted POPAN models, the top four models represented $99.99 \%$ of the weight of evidence (Table 4). All of the top models contained a transient effect in $\varphi$, time dependence in $p$, and pent constant over the specified time bins or linear over time (Time). Otherwise, they only differed because the top two models also contained the effect of 'local' whales having higher recapture probability.

Estimated annual 'apparent survival' was 0.446 (95\% CI: $0.320-0.579)$ in the year after a whale was first seen; whereas, annual survival for subsequent years was 0.919 (95\% CI: 0.850-0.958). The low 'apparent survival' in the first year reflects transient behaviour in which the whales permanently emigrate from the population or more likely do not migrate through the area that was sampled in subsequent years and had very low subsequent recapture probability.

The transient effect in survival influences the estimates of abundance which are decreased because the model predicts the current abundance excluding those that have 'left' the population. The super-population size was estimated to be 5,494 (95\% CI: 3,784-8,491, CV $=0.21)$ but the population size in 2006 was only estimated to be 3,333 (Table 5) or roughly two-thirds of the abundance estimate from the closed model. The difference is reflected in the estimated capture probabilities which are much higher in the POPAN models than the closed models for 2004-2006 (Fig. 2). The open models assume that the whales left (lower apparent survival) and has higher capture probabilities for the remaining whales; whereas, the closed model assumes the abundance is fixed and has lower capture probabilities. We re-fitted the best POPAN model but fixed $\varphi=0.919$ (assumed true survival) based on the assumption that the transients have the same true survival as the non-transients. The model does not fit the data as well but doing so provides an estimated abundance in 2006 of 5,456 which is much more consistent with the closed model result because it is estimating the size of the entire population.

\section{DISCUSSION}

The collaborative effort of two different research groups working in Ecuador (FEMM and PWF) has provided a more reliable estimation of the abundance of southeastern Pacific humpback whale stock (Breeding Stock G) on the breeding grounds. Based on closed models, the abundance estimate in 2006 was about 6,500 whales and 5,500 whales with open models if we assume constant true estimated survival of 0.919 for all whales. Our estimates are higher than previous estimates conducted at breeding grounds (e.g. Capella et al.,

\section{Table 4}

Estimates obtained with the Chapman-modified Petersen estimator $\left(\left[\mathrm{n}_{1}+\right.\right.$ $\left.1]\left[\mathrm{n}_{2}+1\right] /[\mathrm{m}+1]\right)$ for consecutive years with sufficient sampling. For each two-year period the number seen in each year are $n_{1}$ and $n_{2}$, the number of whales re-sighted is $m$, population estimate is $N$ with its $95 \% \log$-normal confidence interval $(\mathrm{CI})$ and coefficient of variation $(\mathrm{CV})$.

\begin{tabular}{lrrrrrr}
\hline Period & $n_{1}$ & $n_{2}$ & $m$ & $N$ & CI 95\% & CV \\
\hline $1996-97$ & 84 & 62 & 5 & 892 & $460-1,726$ & 0.35 \\
$2001-02$ & 47 & 147 & 3 & 1,775 & $802-3,929$ & 0.42 \\
$2002-03$ & 147 & 187 & 8 & 3,091 & $1,741-5,486$ & 0.30 \\
$2003-04$ & 187 & 369 & 26 & 2,575 & $1,855-3,574$ & 0.17 \\
$2004-05$ & 369 & 407 & 27 & 5,390 & $3,855-7,538$ & 0.17 \\
$2005-06$ & 407 & 286 & 17 & 6,504 & $4,270-9,907$ & 0.22 \\
\hline
\end{tabular}

Model selection results for the best 4 of the fitted POPAN models and the POPAN equivalents for models $\mathrm{B}, \mathrm{A}$, and $\mathrm{D}$ in program JOLLY in the bottom 3 rows, respectively.

\begin{tabular}{lccrcrc}
\hline Phi & $p$ & Pent & No. par & AICc & $\Delta$ AICc & Weight \\
\hline transient & time+local & time & 22 & $1,628.32$ & 0.00 & 0.59 \\
transient & time+local & time bins & 24 & $1,629.68$ & 1.44 & 0.29 \\
transient & time & time & 21 & $1,632.23$ & 4.00 & 0.08 \\
transient & time & time bins & 23 & $1,633.54$ & 5.30 & 0.04 \\
constant & time & time & 32 & $1,669.24$ & 41.01 & 0.00 \\
time & time & time & 45 & $1,691.37$ & 63.14 & 0.00 \\
constant & constant & constant & 4 & $2,573.07$ & 944.84 & 0.00 \\
\hline
\end{tabular}


Table 5

Model averaged estimates, 95\% log-normal confidence intervals and coefficient of variation (CV) for humpback whale abundance from open population models.

\begin{tabular}{lrrr}
\hline Year & $\mathrm{N}$ & $95 \% \mathrm{CI}$ & $\mathrm{CV}$ \\
\hline 1991 & 1,260 & $268-5,929$ & 0.93 \\
1992 & 1,218 & $294-5,053$ & 0.83 \\
1993 & 1,182 & $325-4,301$ & 0.74 \\
1994 & 1,156 & $364-3,677$ & 0.65 \\
1995 & 1,138 & $410-3,158$ & 0.56 \\
1996 & 1,129 & $465-2,742$ & 0.48 \\
1997 & 1,122 & $525-2,396$ & 0.40 \\
1998 & 1,134 & $597-2,156$ & 0.34 \\
1999 & 1,179 & $686-2,026$ & 0.28 \\
2000 & 1,249 & $788-1,982$ & 0.24 \\
2001 & 1,359 & $904-2,044$ & 0.21 \\
2002 & 1,509 & $1,017-2,240$ & 0.20 \\
2003 & 1,697 & $1,102-2,613$ & 0.22 \\
2004 & 2,098 & $1,486-2,962$ & 0.18 \\
2005 & 2,798 & $2,043-3,833$ & 0.16 \\
2006 & 3,333 & $2,326-4,775$ & 0.18 \\
\hline
\end{tabular}

1998; Castro et al., 2004; Félix and Haase, 2001a) but concordant with others obtained by Stevick et al. (2006) with a feeding-breeding approach and the one obtained during IDCR/SOWER circumpolar surveys (Branch, 2011). Furthermore, our estimate is slightly lower but within the interval of the IDCR/SOWER estimate projected to 2006 of 6,973 whales (CI 95\% 4,845-8,626) (IWC, 2006).

However, even with the increased effort and collaboration there are still some uncertainties about the results from both the closed and open models. The Petersen estimator is robust to failure of closure as long as there are losses (consistent across all individuals) or gains (Kendall, 1999; Seber, 1982) but not both, except under some circumstances (Kendall, 1999). For our study, there are likely to be both gains and losses from births and deaths and from temporary emigration if some whales, primarily females, do not always return to the breeding grounds each year. Also, it is quite likely that there is unmodelled heterogeneity (variation) in capture

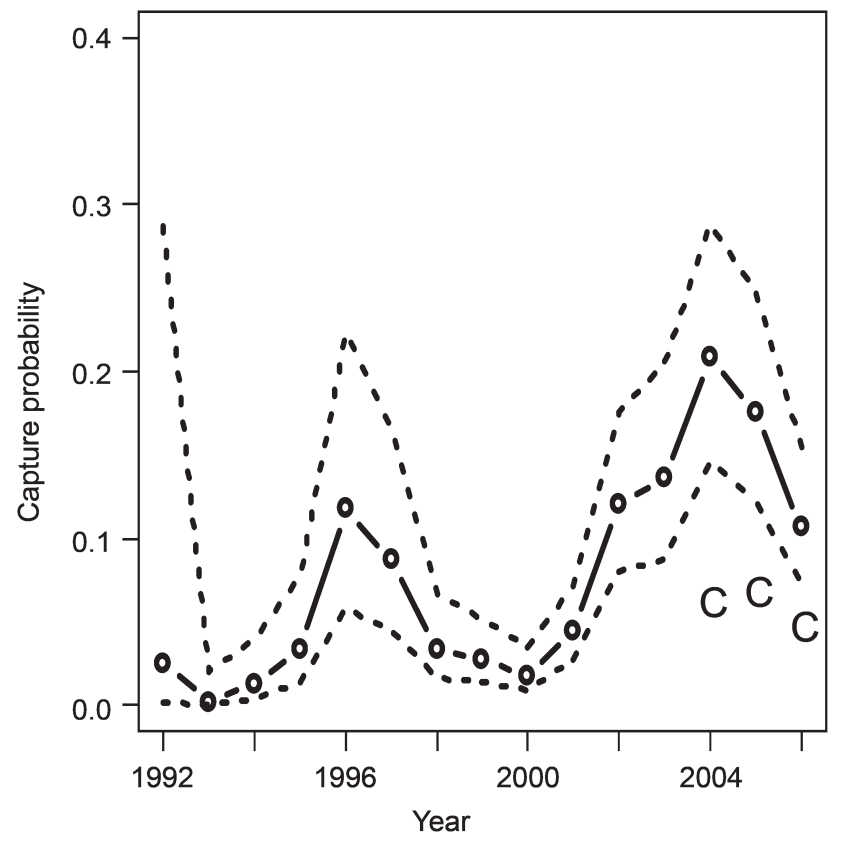

Fig. 2. Model averaged capture probability estimates from POPAN models with $95 \%$ confidence intervals (dashed lines) and closed model capture probability estimates ('C') for 2004-2006 probabilities. Possible sources of heterogeneity in capture probability at breeding grounds have been addressed elsewhere including individual variation in behaviour, habitat use and migration timing (e.g. Hammond, 1986; Palsbøll et al., 1997; Smith et al., 1999; Stevick et al., 2003) as well as the sex ratio in the sample (Olavarria et al., 2007; Palsbøll et al., 1997; Smith et al., 1999). Such topics have not yet been fully addressed in this population, but a major source of heterogeneity in this study was related to the uneven distribution of sampling on the breeding grounds (Table 2) and the heterogeneity introduced from some whales simply migrating by or through the sampling area off Ecuador and breeding near Colombia and Panama and others that remained in or around Ecuador for breeding. Typically, heterogeneity causes negative bias (Kendall, 1999) because there is a positive correlation in capture probabilities across occasions if some whales have higher/lower capture probabilities that remain consistent across occasions. However, it is also possible to introduce a positive bias in abundance if there is a negative correlation in capture probabilities between occasions. An example would be a shift in the timing of sampling within the years if whales are fairly regimented in their migration timing. For example, if there was high effort during the tails of the migration (June, September) in year 1 and low effort in year 2, then capture probability for whales that regularly passed Ecuador during June or September would be negatively correlated. A similar negative correlation occurs with temporary emigration.

Ideally, these data would be modelled as an open population because the population is subject to both gains and losses and this allows simultaneous modelling of all 16 years of the data with presumably an increase in precision. Also, it provides the added benefit of yielding an estimate of annual survival. Even though the open model is more biologically realistic, the realities of the sampling situation and whale migration pose some formidable problems. Heterogeneity in capture probabilities affects open models as well. Our modelling showed that whales seen on multiple days within a year were more likely to be seen in the following years. The use of this covariate for 'local' whales improved the model fit but surely did not completely eliminate capture heterogeneity because it could only be used to remove heterogeneity after the whale was identified as 'local' by sighting it multiple days within the year and certainly there are some 'local' whales that were not seen on multiple occasions.

While unmodelled heterogeneity primarily introduces bias in abundance estimators it can also affects survival estimates. A positive bias in $p$ due to heterogeneity will introduce a negative bias in $\varphi$ because the parameters enter the models as products and thus are negatively correlated. In addition, $\varphi$ is apparent survival which incorporates permanent emigration. Permanent emigration and some forms of heterogeneity can be confounded in the model. These are issues here because whales are being sampled in one portion of the migratory corridor. Consider a whale that typically breeds to the north of Ecuador and typically migrates to the west of the study area. Now assume that in one year it migrates through the study area and is seen but in all future years it continues its normal pattern. This appears to the model as permanent emigration but it should really be viewed as capture heterogeneity which is termed a 'behavioural' effect (trap shy). Once 'caught' the whale is less likely to be caught. This is an analogy to standard small mammal capture-recapture concepts and we are not saying that the whale modified its behaviour from being 
photographed. However, an unknown structure in both the migration timing and corridor can introduce numerous sources of heterogeneity. This heterogeneity is being captured in the 'transient' effect in which estimated 'apparent survival' for the year after first 'capture' is only 0.446 which means about one-half of the whales are never seen again but most are alive. The whales have effectively emigrated from the study area 'population'. The estimated survival rate in subsequent years of 0.919 is a better representation of true survival but it may also be biased low by remaining heterogeneity because it is lower than the survival reported for other humpback whale populations such as those in the Northeastern Pacific (Survival $=0.96$ ) (Calambokidis and Barlow, 2004; Mizroch et al., 2004) and the North Atlantic (Survival $=0.95$ and 0.96) (Barlow and Clapham, 1997; Clapham et al., 2003).

\section{CONCLUSION}

For management purposes, it is necessary to define whether the new estimates presented in this study are representative of the entire Southeast Pacific population (Breeding Stock $\mathrm{G})$ or just a part of it. The available information suggests a complex migrating pattern and different habitat use by humpback whales in the breeding area that needs to be better understood for appropriate modelling. Despite the improvement in the estimates obtained, the current estimates likely represent only part of the population inhabiting the entire Southeast Pacific. Therefore, major efforts are still required to reduce the current level of uncertainty. One of the challenges in future assessments of this population at breeding grounds is obtaining a representative sample of a population distributed over $1,500 \mathrm{~km}$ along the coast of South and Central America, from the north of Peru to Panama/Costa Rica and perhaps even further north (FlórezGonzález et al., 1998; Rasmussen et al., 2007). The easier alternative is to increase the photo-identification sample by bringing together catalogues of institutions working with this population in other countries (e.g. Colombia, Panama and Costa Rica). In addition, it would be useful to carry out an analysis using samples from breeding and feeding grounds. Such an approach has been demonstrated to be more consistent than those using only within-breeding or withinfeeding grounds data (e.g. Smith et al., 1999; Stevick et al., 2006). A larger sample size would also help to improve our knowledge of other population parameters such as survival and birth rates, population growth rates and movements, all of which are still poorly known for this population.

It has been demonstrated here that whalewatching vessels are a valuable research platform for mark-recapture studies due to the near-coastal distribution of humpback whales. Although research activities are rather limited aboard whalewatching boats, they represented a unique and inexpensive opportunity for data collection. One advantage of using whalewatching boats was that (once the operations were well established in the country) there was the opportunity to work during the entire season with similar effort, thus improving data quality and reducing bias due to whale migration behaviour. On the other hand, the preference of whalewatching boats to approach more visible groups or groups with breaching individuals, as well as repeated surveying over the same coastal areas, likely violates the assumption of random sampling as required by markrecapture models. The extent of such biases is difficult to assess in a study like this because the information came from three different sites and was taken onboard of different boats and therefore boat operations, geographic conditions and habitat use by the whales could not be the same in every studied site as we had originally assumed.

\section{ACKNOWLEDGEMENTS}

The authors thank the tourist operators of Puerto López and Salinas, especially to Mantarraya Tours, Macchiavelo Tours, Caroltour, Costatur and Avistatravel, who allowed us to use their boats as research platforms. To the Association of Naturalistic Guides and captains of the Machalilla National Park. C. Castro and M. Scheidat thank the Pacific Whale Foundation for their logistic and economic support. Alex Zerbini and one anonymous reviewer read the manuscript and made valuable suggestions to improve it. FEMM research in Ecuador was supported partially by the Whale and Dolphin Conservation Society (WDCS).

\section{REFERENCES}

Barlow, J. and Clapham, P.J. 1997. A new birth-interval approach to estimating demographic parameters of humpback whales. Ecology 78(2): 535-46.

Branch, T.A. 2011. Humpback abundance south of $60^{\circ} \mathrm{S}$ from three complete circumpolar sets of surveys. J. Cetacean Res. Manage. (special issue 3): 53-69.

Burnham, K.P. and Anderson, D.R. 2002. Model Selection and Multimodel Inference: a Practical Information-theoretic Approach. 2nd ed. SpringerVerlag, New York. 488pp.

Caballero, S., Hamilton, H., Jaramillo, H., Capella, J., Flórez-González, L., Olavarría, C., Rosenbaum, H.C., Guhl, F. and Baker, C.S. 2001. Genetic characterisation of the Colombian Pacific Coast humpback whale population using RAPD and mitochondrial DNA sequences. Mem. Queensl. Mus. 47: 459-64.

Calambokidis, J. and Barlow, J. 2004. Abundance of blue and humpback whales in the eastern North Pacific estimated by capture-recapture and line-transect methods. Mar. Mammal Sci. 20(1): 63-85.

Capella, J., Flórez-González, L., Falk, P. and Celis, G.A. 1998. Population size of southeastern Pacific humpback whale stock. Is it recovering? pp.23. Abstracts of the World Marine Mammal Science Conference, Monaco, 20-24 January 1998. 159pp.

Castro, C. and González, J. 2002. Población de la ballena jorobada Megaptera novaeangliae Balaenopteridae, en el Parque Nacional Machalilla, Ecuador. Doctorate, Universidad Central del Ecuador. 130pp. [In Spanish].

Castro, C., Forestell, P., Kaufman, G. and Scheidat, M. 2004. Ocurrencia, abundancia y residencia de las ballenas jorobadas Megaptera novaeangliae en una area de reproduccion en costas ecuatorianas. XI Reunion de trabajo de especialistas en mamiferos marinos de America del sur, del 11 al 17 de Septiembre de 2004, Quito, Ecuador. p.56-57 [Abstract].

Chapman, D.G. 1951. Some properties of the hypergeometric distribution with applications to zoological censuses. Univ. Calif. Publ. Statist. 1: 131-60.

Chapman, D.G. 1974. Status of the Antarctic rorqual stocks. pp.218-38. In: Schevill, W.E. (eds). The Whale Problem, A Status Report. Harvard University Press, Massachusetts. $\mathrm{x}+419 \mathrm{pp}$.

Clapham, P., Robbins, J., Brown, M., Wade, P. and Findlay, K. 2001. Report of the Scientific Committee. Annex G. Report of the Sub-Committee on the Comprehensive Assessment of Whale Stocks - In-depth Assessments. Appendix 5. A note on plausible rates of population growth in humpback whales. J. Cetacean Res. Manage. (Suppl.) 3: 196-97.

Clapham, P., Barlow, J., Bessinger, M., Cole, T., Mattila, R., Pace, R., Palka, D., Robbins, J. and Seton, R. 2003. Abundance and demographic parameters of humpback whales from the Gulf of Maine, and stock definition relative to the Scotian shelf. J. Cetacean Res. Manage. 5(1): 13-22.

Clarke, R. 1962. Whale observation and whale marking off the coast of Chile in 1958 and from Ecuador towards and beyond the Galápagos Islands in 1959. Norsk Hvalfangsttid. 51(7): 265-87.

Clarke, R. 1980. Catches of sperm whales and whalebone whales in the southeast Pacific between 1908-1975. Rep. int. Whal. Commn 30: 28588.

Félix, F. and Haase, B. 2001a. The humpback whale off the coast of Ecuador, population parameters and behavior. Revista de Biología Marina y Oceanografia 36(1): 61-74. 
Félix, F. and Haase, B. 2001b. Towards an estimate of the southeastern Pacific humpback whale stock. J. Cetacean Res. Manage. 3(1): 55-58.

Félix, F. and Haase, B. 2003. Humpback whale research and education activities in Ecuador during 2003. Report to the Whale and Dolphin Conservation Society, WDCS, Bath, England. 27pp (unpublished, Guayaquil, December 2003). [Available from the author].

Félix, F. and Haase, B. 2005. Distribution of humpback whales along the coast of Ecuador and management implications. J. Cetacean Res. Manage. 7(1): 21-29.

Flórez-González, L. 1991. Humpback whales, Megaptera novaeangliae in the Gorgona Island, Colombian Pacific breeding waters: population and pod characteristics. Mem. Queensl. Mus. 30(2): 291-95.

Flórez-González, L., Capella, J., Haase, B., Bravo, G.A., Félix, F. and Gerrodette, T. 1998. Changes in winter destinations and the northernmost record of southeastern Pacific humpback whales. Mar. Mammal Sci. 14(1): 189-96.

Gibbons, J., Capella, J.J. and Valladares, C. 2003. Rediscovery of a humpback whale, Megaptera novaeangliae, feeding ground in the Straits of Magellan, Chile. J. Cetacean Res. Manage. 5(2): 203-08.

Haase, B. 1990. Study of the humpback whale Megaptera novaeangliae in Ecuador, with an estimation of the eastern tropical Pacific stock boundaries. Progress Report to Whale and Dolphin Conservation Society, Bath, England. 11pp (unpublished). [Available from the author].

Hammond, P.S. 1986. Estimating the size of naturally marked whale populations using capture-recapture techniques. Rep. int. Whal. Commn (special issue) 8: 253-82.

International Whaling Commission. 2006. Report of the Scientific Committee. Annex H. Report of the Sub-Committee on the Other Southern Hemisphere Whale Stocks. J. Cetacean Res. Manage. (Suppl.) 8:151-70.

Katona, S., Baxter, B., Brazier, O., Kraus, S., Perkins, J. and Whitehead, H. 1979. Identification of humpback whales by fluke photographs. pp.3344. In: Winn, H.E. and Olla, B.L. (eds). Behaviour of Marine Mammals, Vol. 3: Cetaceans. Plenum Press, New York and London. i-xix $+438 \mathrm{pp}$.

Kendall, W.L. 1999. Robustness of closed capture-recpature methods to violations of the closure assumption. Ecology 80(8): 2517-25.

Laake, J. and Rexstad, E.A. 2008. RMark - an alternative approach to building linear models in MARK. In: Cooch, E. and White, G.C. (eds) Program MARK: a gentle introduction. 690pp. [Available at: http://www.phidot.org/software/mark/docs.book].

Mizroch, S.A., Herman, L.M., Straley, J.M., Glockner-Ferrari, D.A., Jurasz, C., Darling, J., Cerchio, S., Gabriele, C.M., Salden, D.R. and von Ziegesar, O. 2004. Estimating the adult survival rate of central north Pacific humpback whales (Megaptera novaeangliae). J. Mammal. 85(5): 963-72.

Ojeda, Z.V. and Hurtado, L.A. 1992. Aspectos biológicos de la yubarta Megaptera novaeangliae durante su ciclo reproductivo en la isla Gorgona, 1991. Memorias del VIII Seminario de Ciencias y Tecnologias del Mar y Congreso Centroamericano y del Caribe de Ciencias del Mar. Santa Marta. Colombia. pp.697-708. [In Spanish]

Olavarria, C., Baker, C.S., Garrigue, C., Poole, M., Hauser, N., Caballero, S., Florez-Gonzalez, L., Brasseur, M., Bannister, J., Capella, J., Clapham, P., Dodemont, R., Donoghue, M., Jenner, C., Jenner, M.N., Moro, D., Oremus, M., Paton, D. and Russell, K. 2007. Population structure of
South Pacific humpback whales and the origin of the eastern Polynesian breeding grounds. Mar. Ecol. Prog. Ser. 330: 257-68.

Palsbøll, P.J., Allen, J., Bérubé, M., Clapham, P.J., Feddersen, T.P., Hammond, P.S., Hudson, R.R., Jórgensen, H., Katona, S., Larsen, A.H. Larsen, F., Lien, J., Mattila, D.K., Sigurjónsson, J., Sears, R., Smith, T., Sponer, R., Stevick, P. and Øien, N. 1997. Genetic tagging of humpback whales. Nature 388(6644): 767-69.

$R$ Development Core Team. 2008. $R$ : a language and environment for statistical computing. R Foundation for Statistical Computing, Vienna, Austria. [ISBN: 3-900051-07-0 http://www.R-project.org].

Ramírez, P. 1988. La ballena jorobada Megaptera novaeangliae en la costa norte del Perú. Periodos 1961-1966 y 1975-1985. Bol. Lima 56: 91-96. [In Spanish].

Rasmussen, K., Palacios, D., Calambokidis, J., Saborio, M.T., Dalla Rosa, L., Secchi, E.R., Steiger, G.H., Allen, J.M. and Stone, G. 2007. Southern Hemisphere humpback whales wintering off Central America: insights from water temperature into the longest mammalian migration. Biology Letters 3(3): 302-05.

Scheidat, M., Castro, C., Denkinger, J., González, J. and Adelung, D. 2000 A breeding area for humpback whales (Megaptera novaeangliae) off Ecuador. J. Cetacean Res. Manage. 2(3): 165-72.

Schwarz, C.J. and Árnason, A.N. 1996. A general methodology for the analysis of open-model capture-recapture experiments. Biometrics 52 : 860-73

Seber, G.A.F. 1982. The Estimation of Animal Abundance and Related Parameters. 2nd ed. Charles Griffin and Company Ltd., London. ixvii+654pp.

Smith, T.D., Allen, J., Clapham, P.J., Hammond, P.S., Katona, S., Larsen, F., Lien, J., Mattila, D., Palsbøll, P.J., Sigurjónsson, J., Stevick, P.T. and Øien, N. 1999. An ocean-basin-wide mark-recapture study of the North Atlantic humpback whale (Megaptera novaeangliae). Mar. Mammal Sci. 15(1): 1-32

Stevick, P.T., Allen, J., Clapham, P.J., Friday, N., Katona, S.K., Larsen, F., Lien, J., Mattila, D.K., Palsbøll, P.J., Sigurjónsson, J., Smith, T.D., Øien, N. and Hammond, P.S. 2003. North Atlantic humpback whale abundance four decades after protection from whaling. Marine Ecology. Progress Series 258: 263-73.

Stevick, P.T., Aguayo, A., Allen, J., Avila, I.C., Capella, J., Castro, C., Chater, K., Dalla Rosa, L., Engel, M.H., Felix, F., Florez-Gonzalez, L., Freitas, A., Haase, B., Llano, M., Lodi, L., Munoz, E., Olavarria, C., Secchi, E., Scheidat, M. and Siciliano, S. 2004. Migrations of individually identified humpback whales between the Antarctic peninsula and South America. J. Cetacean Res. Manage. 6(2): 109-13.

Stevick, P.T., Aguayo-Lobo, A., Allen, J.M., Castro, C., Chater, K., Dalla Rosa, L., Félix, F., Haase, B., Llano, M., Olavarria, C., Rasmussen, K. and Secchi, E. 2006. Estimated abundance of humpback whales off the west coast of central and South America (Group G). Paper SC/A06/HW56 presented to the IWC Workshop on Comprehensive Assessment of Southern Hemisphere Humpback Whales, Hobart, Tasmania, 3-7 April 2006 (unpublished). 9pp. [Paper available from the Office of this Journal].

White, G.C. and Burnham, K.P. 1999. Program MARK: Survival estimation from populations of marked animals. Bird Study 46(Supplement): 120 38 . 